\title{
Site-specific gene cassette insertion by combining artificial restriction DNA cutter and single-stranded DNA specific endonuclease
}

\author{
Hitoshi Katada, Narumi Shigi,* and Makoto Komiyama* \\ Research Center for Advanced Science and Technology, The University of Tokyo, 4-6-1 Komaba, \\ Meguro, Tokyo 153-8904, Japan \\ E-mail: komiyama@mkomi.rcast.u-tokyo.ac.jp; narumi@mkomi.rcast.u-tokyo.ac.jp
}

This paper is dedicated to Professor Harri Lönnberg on the occasion of his $60^{\text {th }}$ birthday

\begin{abstract}
An artificial restriction DNA cutter (ARCUT), which was composed of Ce(IV)/EDTA complex and a pair of pseudo-complementary peptide nucleic acid, was used for construction of recombinant plasmid vector. The plasmid vector was cut by ARCUT only at target site, and resultant specific overhangs were blunted by treatment with Mung Bean Nuclease and Klenow fragment. This fragment having blunt ends at both termini was ligated with the gene of enhanced green fluorescent protein (EGFP) prepared by PCR. The resultant recombinant vector was translated and the fluorescent protein was successfully expressed in cells. Throughout the manipulation, neither natural restriction enzymes nor homologous recombination was employed. Thus, this strategy has promising applicability to construction of still larger vectors.
\end{abstract}

Keywords: Cerium, peptide nucleic acid, single-stranded DNA specific endonuclease, gene manipulation

\section{Introduction}

In current biology and biotechnology, small vectors (e.g., plasmid vectors) are constructed by cutting plasmids with restriction enzymes, followed by connection of an insert to this vector using ligase. In this case, we choose from a number of commercially available restriction enzymes one that recognizes the target sites. On the other hand, in constructing larger vectors such as virus vectors, available methods are limited to homologous recombination for the following reasons. First, recognition sequences of restriction enzymes are limited so that we often encounter difficulty in finding an appropriate one to cut the vectors. Second, most of the available restriction enzymes 
recognize 4-6 DNA-base sequences, and thus their digestions occur at too many sites, forming fragmented DNA which is unable to be used for further manipulation. For these reasons, a powerful tool for the manipulation of large DNA has been strongly desired. ${ }^{1-8}$

Recently, we have developed artificial restriction DNA cutter (ARCUT) for site-specific hydrolysis of double-stranded DNA. ${ }^{9-12}$ This new tool is composed of Ce(IV)/EDTA complex, which selectively hydrolyzes single-stranded portion in double-stranded DNA, and a pair of pseudo-complementary peptide nucleic acid (pcPNA). The recognition sites and site specificity of ARCUT can be tuned simply by changing the pcPNAs. Thus, ARCUT is applicable to construction of vectors of various sizes. However, the specific structures of termini of the ARCUT scission fragments, which are not complementary to the termini of any restriction enzymes, raise some difficulty for the subsequent ligation process. In order to resolve this problem, we here employed Mung Bean Nuclease, a single-stranded DNA specific endonuclease, to blunt the termini of the ARCUT scission fragments. Then, the PCR amplified EGFP gene cassette was ligated with this vector. Since neither natural restriction enzymes nor homologous recombination is required in this procedure, this method should be applicable to the recombination of still larger vectors.

\section{Results and Discussion}

The outline of the gene manipulation in this study is depicted in Figure 1. As mentioned above, overhangs of about 15 bases are formed after ARCUT scission. This fragment was treated with Mung Bean Nuclease and Klenow fragment to form blunt ends completely, and the EGFP gene cassette was ligated using DNA ligase. 


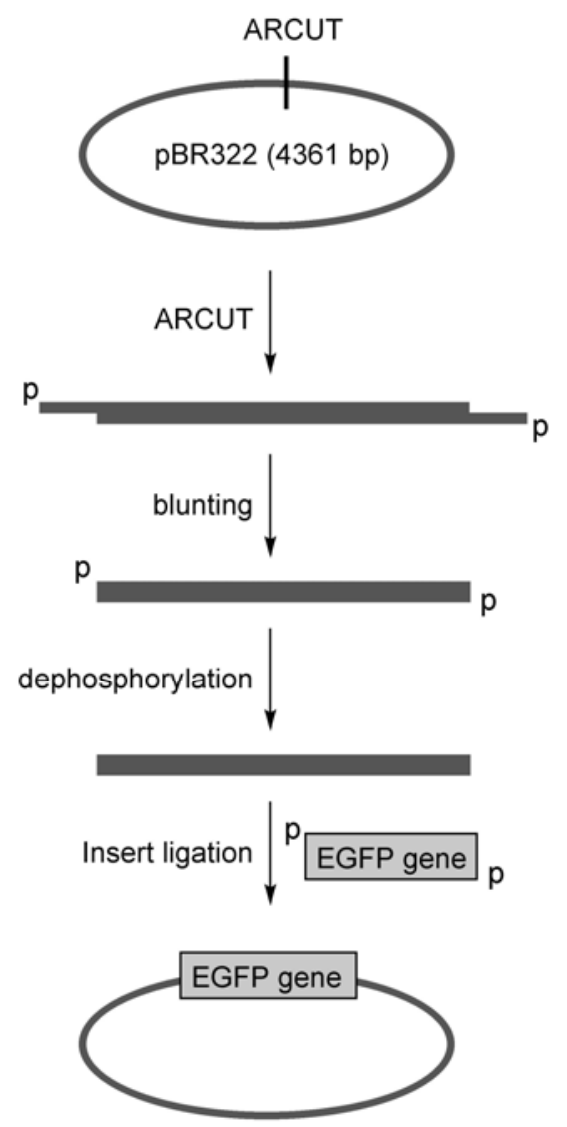

Figure 1. Outline of this work.

\section{Scission of pBR322 by ARCUT}

In order to cut the pBR322 plasmid at the 1830 bp site, ARCUT was designed as follows. First, the plasmid was incubated with two pcPNA additives, $\mathrm{pcPNA}^{(1)}$ and $\mathrm{pcPNA}^{(2)}$, whose sequences are given in Figure 2a. These additives are complementary to C1826-A1840 in the upper strand and A1821-G1835 in the lower strand, respectively. After invasion complex was formed, T1821-T1825 in the upper strand and G1836-T1840 in the lower strand were kept single-stranded. These single-stranded portions were selectively hydrolyzed by Ce(IV)/EDTA complex. The scission fragments were analyzed by $0.8 \%$ agarose gel electrophoresis. As shown in lane 3 of Figure 2b, linearized 4361 bp fragment was formed. In order to confirm the site-specificity of ARCUT scission, this mixture was further treated with EcoRI, whose recognition site was located at $4359 \mathrm{bp}$ site of this plasmid. As shown in lane 4, only $1.8 \mathrm{kbp}$ and $2.5 \mathrm{kbp}$ fragments were formed, indicating that ARCUT scission occurred only at the target site (the $4361 \mathrm{bp}$ fragment was formed by digestion of open-circular DNA with EcoRI). 
(a)

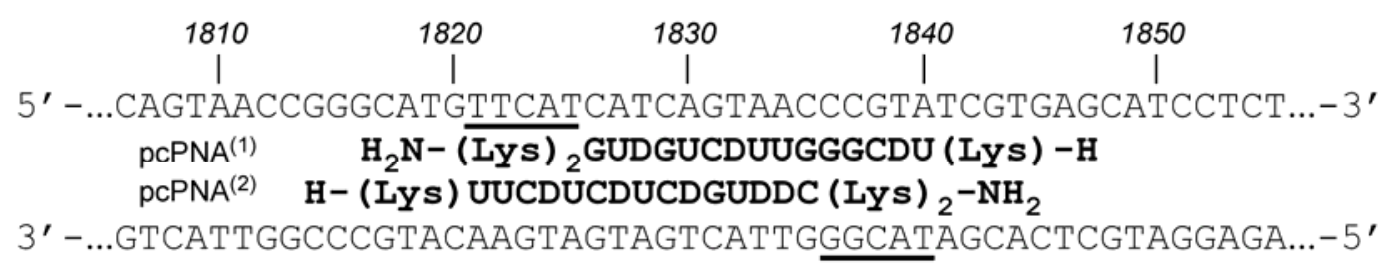

(b)

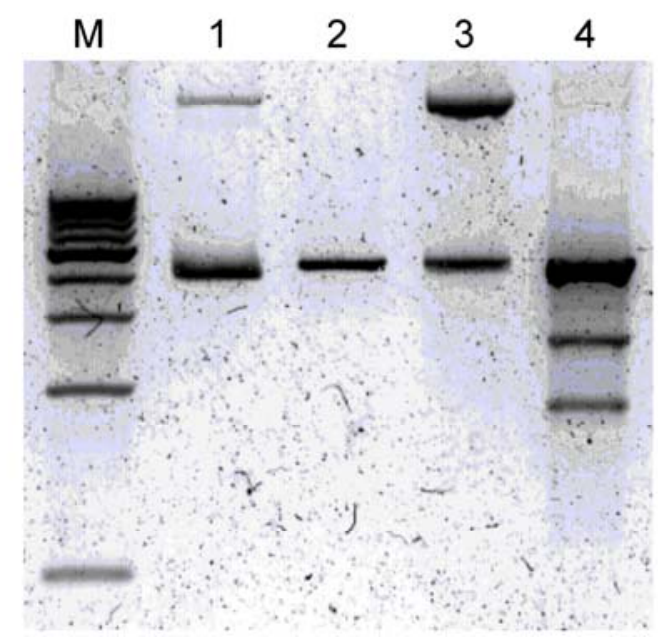

Figure 2. (a)Sequences of pcPNA additives and DNA around target site (the single-stranded portions in both strands of the DNA are underlined). (b) Gel electrophoresis patterns for the scission of pBR322. Lane M, 1 kbp DNA ladder; Lane 1, supercoiled pBR322; Lane 2, linearized pBR322 digested by AvaI; Lane 3, after ARCUT treatment of supercoiled pBR322; Lane 4, EcoRI digests of the products in lane 3 .

\section{Blunting of the scission fragments and preparation of recombinant vector}

After the ARCUT scission, the 4361 bp linear fragment was isolated from the gel, and treated with Mung Bean Nuclease, to form the blunt ends. This blunting was further completed by additional treatment with Klenow fragment. Then the terminal phosphates were removed by alkaline phosphatase to prevent the self-ligation of the vector. This vector was ligated with the phosphorylated EGFP gene cassette, which was prepared by PCR amplification followed by phosphorylation using T4 polynucleotide kinase, and transformed into E.coli. The insertion of EGFP gene cassette was confirmed in five of sixteen randomly selected colonies. After extraction of plasmids from cells, the sequences of these sixteen plasmids were analyzed. One of the sequencing results of the positive plasmids is shown in Figure 3a. The EGFP gene cassette was successfully inserted into the target site of the vector and translated in cells as shown in Figure 3b. 
(a)
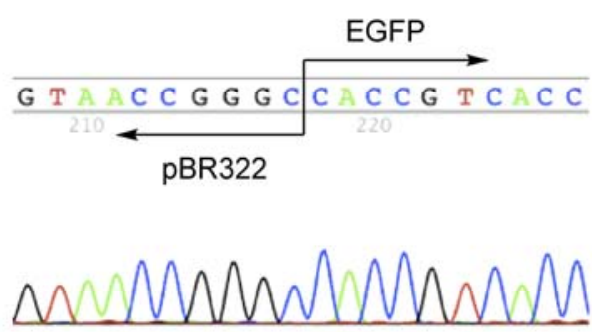

(b)

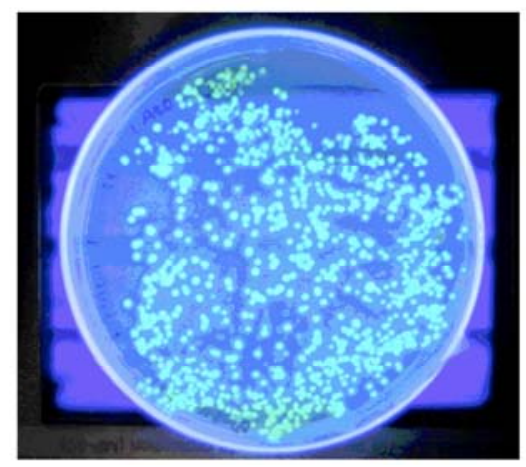

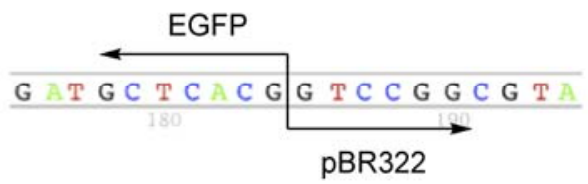

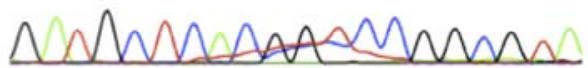

Figure 3. (a) Sequencing analysis of the recombinant vector in which EGFP gene was inserted at forward (left) and reverse (right) conjunction sites, respectively. (b) Emission of fluorescence from the EGFP expressed in BL21-Gold (DE3).

\section{Direction of the insertion of EGFP}

In the blunt-end ligation, the EGFP gene cassette could be ligated with the vector in two ways. More specifically, the promoter, at one end of the EGFP gene cassette could be located either upstream or downstream of the terminator, which is located at the other side of the cassette. In two of five positive plasmids, the EGFP gene cassette was ligated in the former fashion, and the other three was in the latter fashion. All the negative plasmids were found to be original pBR322. This might be attributed to the pcPNA additives that form duplexes with the sticky ends of ARCUT scission product. As previously reported, DNA/PNA duplexes are so stable that displacement of the PNA strand by single-stranded DNA that is complementary to the PNA hardly occurs. ${ }^{13}$ Therefore, these remaining pcPNA strands at the termini of ARCUT scission products could inhibit access of Mung Bean Nuclease and Klenow fragment and formation of blunt ends.

In conclusion, the EGFP gene cassette was site-specifically inserted into a plasmid vector by combining ARCUT and single-stranded DNA specific endonuclease through blunt-end ligation. The fluorescent protein was successfully expressed in cells. In this work, neither natural restriction enzymes nor homologous recombination was used. Therefore, this strategy has promising applicability to construction of virus vectors and also to manipulation of huge genomic DNAs of higher animals and plants. 


\section{Experimental Section}

General procedures. Water was deionized by MILLIPORE WATER PURIFICATION SYSTEM, and sterilized immediately before use. The $\mathrm{Ce}^{4+} / \mathrm{EDTA}$ solution was prepared by mixing an aqueous solution of $\mathrm{Ce}\left(\mathrm{NH}_{4}\right)_{2}\left(\mathrm{NO}_{3}\right)_{6}(20 \mathrm{mM}$ : Nacalai Tesque) and EDTA·4Na (20 mM: Tokyo Kasei Kogyo) in HEPES buffer, and then adjusting the $\mathrm{pH}$ to 7.0 with a small amount of $\mathrm{NaOH}$. The synthesis, purification, and characterization of pcPNA additives were previously reported. ${ }^{14}$

\section{Scission of pBR322 by ARCUT}

The pBR322 plasmid DNA (TAKARA) was hydrolyzed by ARCUT under the following conditions: $[\mathrm{pBR} 322]=8 \mathrm{nM}$, [each PNA] $=100 \mathrm{nM},\left[\mathrm{Ce}^{4+} /\right.$ EDTA $]=100 \mu \mathrm{M}$, and $[\mathrm{NaCl}]=100$ $\mathrm{mM}$ at $\mathrm{pH} 7.0$ (5 mM HEPES buffer), $37^{\circ} \mathrm{C}$ for $72 \mathrm{~h}$, and reaction was stopped by adding ethylenediaminetetramethylenephosphonic acid to a final concentration of $500 \mu \mathrm{M}$. In order to remove PNAs, two oligonucleotides, which are complementary to pcPNA1 and pcPNA2, respectively were added to a final concentration of $5 \mu \mathrm{M}$ and incubated at $50^{\circ} \mathrm{C}$ for $30 \mathrm{~min}$. And then, desired linear fragments were purified by $1 \%$ agarose gel electrophoresis and extracted from the gel by using a QIAquick Gel Extraction Kit (QIAGEN).

\section{Blunting of scission fragments}

The purified product was treated with Mung Bean Nuclease ([the enzyme (TAKARA)] $=0.08$ $\mathrm{U} / \mu \mathrm{l}$, [DNA] $=30 \mathrm{nmol} / \mu \mathrm{l}, 37^{\circ} \mathrm{C}$ for $10 \mathrm{~min}$ ), and then extracted with phenol/chloroform mixture. Furthermore, the product was treated with Klenow fragment to form blunt ends completely $\left([\right.$ Klenow fragment $($ TAKARA $)]=0.0008 \mathrm{U} / \mu \mathrm{l}$, [DNA] $=1.6 \mathrm{fmol} / \mu \mathrm{l}[\mathrm{dNTPs}]=200 \mu \mathrm{M}, 37^{\circ} \mathrm{C}$ for $30 \mathrm{~min}$ ) and purified with a QIAquick PCR Purification Kit (QIAGEN). The product was dephosphorylated with alkaline phosphatase ([calf intestinal alkaline phosphatase (TAKARA)] = $0.3 \mathrm{U} / \mu \mathrm{l},[\mathrm{DNA}]=6 \mathrm{fmol} / \mu \mathrm{l}, 50^{\circ} \mathrm{C}$ for $1 \mathrm{~h}$ ) and then extracted with a phenol/chloroform mixture.

\section{Preparation of the insert}

The EGFP expression cassette was amplified by PCR using the two primers (forward: 5'-CACCGTCACCCTGGATGCTG-3', reverse: 5'-GTCCGGCGTAGAGGATCGAG-3') and pQBI T7-GFP as template under the following conditions: [pQBI T7-GFP (Wako)] = $12 \mathrm{pg} / \mu \mathrm{l}$, [each primer] $=0.3 \mathrm{pmol} / \mu \mathrm{l}$, [dNTPs] $=200 \mu \mathrm{M}$, [PrimeSTAR HS DNA Polymerase (TAKARA)] $=0.025 \mathrm{U} / \mu \mathrm{l}$. Cycling conditions were 30 cycles of $98^{\circ} \mathrm{C}$ for $10 \mathrm{~s}, 55^{\circ} \mathrm{C}$ for $5 \mathrm{~s}$, and $72^{\circ} \mathrm{C}$ for $70 \mathrm{~s}$. After the purification with a QIAquick PCR Purification Kit (QIAGEN), the PCR-amplified 1050 bp product was phosphorylated ([T4 Polynucleotide Kinase (TOYOBO) $]=0.4 \mathrm{U} / \mu \mathrm{l}$, [PCR product $]=50 \mathrm{ng} / \mu \mathrm{l},[\mathrm{ATP}]=1 \mathrm{mM}, 37^{\circ} \mathrm{C}$ for $\left.1 \mathrm{~h}\right)$. After deactivation $\left(70^{\circ} \mathrm{C}\right.$ for $\left.10 \mathrm{~min}\right)$, the product was purified with a QIAquick PCR Purification Kit (QIAGEN). 


\section{Construction of recombinant vector}

To a 1:100 mixture of the vector and the phosphorylated PCR product, the same amount of DNA Ligation kit <Mighty Mix $>$ (TAKARA) was added. After incubation at $16^{\circ} \mathrm{C}$ for $16 \mathrm{~h}$, JM109 (TOYOBO) was transformed with the ligation product and cultured on LB-agar media. 16 colonies were selected randomly and cultured in $3 \mathrm{ml}$ of LB media. The plasmid DNA was extracted from cells by using a QIAprep spin Miniprep Kit (QIAGEN), and its sequences were determined from 200 bp away from the scission sites by using an ABI PRISM 3130 genetic analyzer (Applied Bioscience). In order to confirm the expression of the EGFP, these plasmids were introduced into BL21-Gold (DE3) (stratagene), which intrinsically possesses the T7 RNA polymerase that JM109 does not.

\section{Acknowledgements}

This work was partially supported by a Grant-in-Aid for Scientific Research from the Ministry of Education, Science, Sports, Culture and Technology, Japan. Support by the Global COE Program for Chemistry Innovation is also acknowledged.

\section{References}

1. Komiyama, M.; Sumaoka, J. Curr. Opin. Chem. Biol. 1998, 2, 751.

2. Hegg, E. L.; Burstyn, J. N. Coord. Chem. Rev. 1998, 173, 133.

3. Blasko, A.; Bruice, T. C. Acc. Chem. Res. 1999, 32, 475.

4. Ott, R.; Krämer, R. Appl. Microbiol. Biotechnol. 1999, 52, 761.

5. Flanklin, S. J. Curr. Opin. Chem. Biol. 2001, 5, 201.

6. Suh, J. Acc. Chem. Res. 2003, 36, 562.

7. Liu, C.; Wang, M.; Zhang, T.; Sun H. Coord. Chem. Rev. 2004, 248, 147.

8. Mancin, F.; Scrimin, P.; Tecilla, P.; Tonellato, U. Chem. Commun. 2005, 2540.

9. Komiyama, M.; Aiba, Y.; Yamamoto, Y.; Sumaoka, J. Nat. Protoc. 2008, 3, 655.

10. Yamamoto, Y.; Uehara, A.; Tomita, T.; Komiyama, M. Nucleic Acids Res. 2004, 32, e153.

11. Yamamoto, Y.; Uehara, A.; Watanabe, A.; Aburatani, H.; Komiyama, M. ChemBioChem 2006, 7, 673.

12. Yamamoto, Y.; Mori, M.; Aiba, Y.; Tomita, T.; Chen, W.; Zhou, J. M.; Uehara, A.; Ren, Y.; Kitamura, Y.; Komiyama, M. Nucleic Acids Res. 2007, 35, e53.

13. Grossmann, T. N.; Sasaki, S.; Ritzefeld, M.; Choi, S. W.; Maruyama, A.; Seitz, O. Bioorg. Med. Chem. 2008, 16, 34.

14.Komiyama, M.; Aiba, Y.; Ishizuka, T.; Sumaoka, J. Nat. Protoc. 2008, 3, 646. 